\title{
The Challenges of Environmental Governance: The Case of Mining Activities in Ghana with Emphasis on the Obuasi District of Ghana
}

\author{
Feizel Ayitey Aryee \\ Mphil Environmental Management School Of Public Leadership \\ Stellenbosch University Matieland, Stellenbosch South Africa
}

\begin{abstract}
Ghana is the first nation in Sub-Saharan Africa to attain independence from colonial rule in 1957. The country has numerous natural resources. Ghana is however plagued by poverty and under development. The mining industry is one of the challenging sectors the country is finding difficult to address. The rate of illegal and small scale mining is destroying Ghana's biodiversity. These problems can be address when there is in place functional institutional frameworks. This research will examine Ghana's mining industry against environmental governance frameworks such as co-management, stakeholder consultations, and collaborative environmental governance. This research employed case study approach and the analysis and evaluation of secondary data as well as face to face interview with some miners. At the end of this research, it was concluded that various stakeholders involved with mining in Ghana pursue their own interest to the detriment of the environment and the community in which the mines operate. With the empowerment of governmental institution and the local mining communities, Ghana can ripe a great benefit from its gold mines and also ensure the environment is not degraded to the detriment of future generations.
\end{abstract}

Keywords: environmental governance, sustainable development, illegal gold mining, Ghana.

\section{Introduction}

On March 20, 1987 the Brundtland Commission of the United Nations defined sustainable development as "development that meets the needs of the present without compromising the ability of future generations to meet their own needs". Humans are living on an earth where natural resources are limited and the rate of population growth is astronomically very high. This means, in order to ensure the continual existence of Human Being on Earth, there will be the need for our natural resources to be managed in a manner so as to ensure that future generations have their fair share of the available resources. This is because the resources of the Earth is seen as a public good in the sense that, whatever happens to the Earth's resources does not only affect a specific country in particular but affect the whole Earth in general.

It is in light of this that the phrase 'environmental governance' was coined. Environmental governance is basically a political and environmental term that aims at defining the elements needed to achieve sustainable development or sustainability. The core idea of environmental governance is that all activities of humans including political, economic and social, should be viewed as an integral part of the environment and the ecosystem in general (Oliver et al., 2005:8).

Ojela (2005) defined environmental governance as "all the processes and institutions, both formal and informal, that encompass the standards, values, behaviour and organizing mechanisms used by citizens, organizations and social movements as well as the different interest groups as a basis for linking up their interests, defending their differences and exercising their rights and obligations in terms of accessing and using natural resources". Environmental governance therefore goes beyond governmental framework of management (Executive, Legislative and Judiciary, ministries, government agencies etc.) and incorporates non governmental agencies, international organizations, private businesses and civil societies.

Ghana is an independent state in West Africa. The country was formally known as Gold Coast by the first European settlers due to the abundance of minerals in the country. Ghana is also the second largest producer of Gold in Africa, second to South Africa (Kesse, 1980; Agbesinyale, 2003). It is unfortunate to note however that, with all these natural resources the country has seen little development from the mineral resources being mined. This article will focus on the challenges of environmental governance in the mining industry with specific emphasis on the Obuasi community. Obuasi district is located in the Ashanti Region and it is famous for the location of the AngloGold-Ashanti gold mines. My focus is in this districts because, this district have been one of the main mining towns in Ghana before independence in 1957 and its still one of the man mining districts that generates millions of dollars to the country annually. Unfortunately there has been less or no development in these towns. 


\section{Overview Of Ghana Government Policy \& Program}

There are various actors and agencies responsible for Ghana's mineral resources. The Ministry of Mines and Energy is responsible for overseeing mining and exploitation licenses. They are the overall state agent responsible for the country's mineral sector. Within the Ministry of Mines and Energy the agency responsible for overseeing the Mineral Act is the Minerals Commission. Some of the responsibilities of the Minerals Commissions are: serving as liaison between government and industry, they serve as an advisory body advising government on mineral matters, they also help promote mineral development and they also recommend mineral policies. The Precious Mining Marketing Corporation (PMMC) is a government agency that plays a crucial role in mineral operations in Ghana. They are responsible for ensuring the development of small scale diamond and gold mining activities. They also buy the gold and diamonds from these small scale miners either directly or indirectly from the small scale miners or other agencies.

Mining activities in Ghana are regulated by various legislations but the overall legislative framework regulating mining activities is the Minerals and Mining Law of 1986 (PNDC Law 153). This law has since been amended in 1994 and 2005. Under the Minerals and Mining Act (1986), mining companies in Ghana are required to pay royalties as well as corporate taxes at a specify standard rate. The 1994 amendment of this Act reduced the mining corporate tax to $35 \%$ from the initial $45 \%$. This amendment was necessary to ensure all the industries in Ghana adhere to the same rate of tax. Further amendment to the Minerals Act in 2005 established a duration for a mining lease as well as changes to royalty rates. In 2010 the royalty rate was further change to $5 \%$ from 3\% (ghanaweb.com). There are other legislations which also regulate mineral activities in Ghana and these includes the Small Scale Gold Mining Law (1989), the Investment Promotion Act 1994 (Act 478), The Minerals Royalty Regulation of 1987 (LI 1349), Environmental Protection Agency Act 1994 (Act 490), Environmental Assessment Regulations 1999 (amended 2002) etc.

\section{Theoretical Point Of Departure And Literature Review}

It is an undisputable fact that the resources of the earth are a public good. Public good or resource is a resource that is not owned by a specific group or organization. In 1986, the nuclear power era or regime experienced one of its major catastrophes. The nuclear power station at Chernobyl experienced a major accident to have ever happened in nuclear power generation. This catastrophe happened in Russia but within a few seconds, scientists in major European nations could detect abnormally level of radiation in the environment. This prompted major reforms in nuclear power generation in the world. This simple example is a clear case why environmental issues need to be tackle with a different perspective, that is, in a global context. Whatever pollution one country is generating may not affect that particular country alone but it may have a catastrophic effect elsewhere at the other part of the world.

There have been various literatures as to how to go about solving environmental issues. Hardin in his 1968 journal 'The Tragedy of the Commons' concluded that, natural resources should either be privatized or should be under the direct control of central government. He used the phrase "mutual coercion that is commonly agreed to". There has been various criticism of this accession with some advocating for a communal management involving stakeholders and non-state organization. Environmental issues are therefore treated in the global scale because of its transboundary nature and there have been ground breaking conferences that seek to find solutions to major environmental problems. Major conferences that always come to the lamplight are the conference at Stockholm, Rio and Johannesburg.

Due to the global perspective of environmental governance, there are a number of actors that play crucial roles in coming up with policies and regulation that is geared towards protecting the environment. An important actor in the arena of global environmental governance decision making is the role played by NationState. The main responsibility of a nation is the process of regime formulation. In any conference, Nations assume one of four roles: Either a lead state, supporting state, swing state or a veto (blocking) state. Various factors are taken into considerations before a State will assume one of these four postures in the stage of global environmental governance. One important factor is the influence of domestic economic interest of a particular state and the assessment of cost and benefit of the particular environmental regime under consideration. For instance in the area of marine pollution, countries like Greece, Japan, and Norway will always assume the position of swing or veto state because of the economic gains from their shipping industries whiles countries like the Netherland, Sweden and Italy will tend to assume a more liberal posture because they have smaller shipping industry and they will not be affected in a significant manner by any policy against marine pollution. Various states therefore tend to support a particular environmental regime in the global context only when the policy being proposed is favorable to them. States are also able to assume a particular position when there are no domestic pressures from within its institutions. The United States for instance in the 1970s and 1980s was comfortable in assuming a lead role in the issue of whaling because during those times, the whaling industry was non-existence in the United State and obviously there will be no domestic pressure from the local industry should there be any harsh regulations that may affect the operations of the whaling industry. 
Cost and benefit analysis of environmental compliance by a particular State is also an important factor that is taken into consideration during a regime negotiations. Obviously, a State will support a regime if and only if the benefits from the proposed regime change will far out-weight the cost (economic interest). During the Kyoto protocol negotiation on reduction of greenhouse gas such as Chlorofluorocarbon (CFC), the main issue being debated was the cost that the individual states will incur if CFCs are phased out completely. Also during the Montreal Protocol negotiations, Mostafa Tolba, who was the executive director of the United Nations Environmental Program (UNEP) was quoted in saying that "The difficulties in negotiating the Montreal Protocol had nothing to do with whether the environment was damaged or not... it was all who was going to get the edge over whom"' (Porter et al., 2000:35-78).

International organizations (IOs) also known as Intergovernmental Organizations play a major role on the global environmental arena during regime change negotiation. The major roles of IO are the sponsorships of negotiations and also the implementation of developments, setting agendas and programs on the global scales. Prominent among major IOs are the Food and Agriculture Organizations (FAO), World Health Organization (WHO), UNEP, etc. The most influential IOs are multilateral financial institutions such as the World Bank and the International Monetary Fund's (IMF). This is because these institutions have a direct impact on the policies of especially developing countries by the provision of financial aids. There have however been various discussions about the activities of these multilateral institutions with some arguing that their activities are rather detrimental to the environment because their core values is profit or economic gains at the expense of environmental protection. This assertion was true with especially the IMF as they argue that their core responsibility is assisting countries achieve balance of payments and assisting member countries with the payments of their debts.

Non-Governmental Organizations also play a fair crucial role in environmental regime formulation and their inputs especially at the global level has helped shaped the kind of decisions taken by states and major actors in environmental regime formulation. NGOs have various ways of influencing regime changes, firstly, some NGOs which are well staffed technically, are able to write a draft convention very well in advance before the commencement of negotiations. NGOs are also able to provide technical information's to delegates that are sympathetic or agrees with their course of actions. An important activity of NGOs is the monitoring of compliance with an established agreement and reporting on non-compliance. Private enterprises also play a major role in environmental regime negotiations because whatever decision is taken in the global stage may affect their activities directly or indirectly. Most private corporations have ease access to decision makers in influencing government sectors and organizations; they are therefore able to directly influence most state organs even before they embark on any international conference.

It is very important to note at this point that, many policy makers fail to see environmental issues as policy problems. It is interesting that, when environmental problems first arose, most policy makers assumed a technocentric posture. This posture treated environmental problems as a negative feedback of economic growth. The traditional idea was to establish a Ministry of Environment to deal with environmental problems as is done with any other policy problems. The issue of the environment however goes beyond the establishment of a specific governmental department to deal with it. This is because the environment is a public good in that, one person refraining from polluting the environment does not prevent the other person from polluting the environment. And the consequence of one's polluting activity unfortunately is borne by all and sundry. The environment is therefore seen in two ways. First of all as a common-pool resource. This includes fish stock, fuana and forest. Secondly, it can be seen as a common-sink resource such as the air we breathe. It is very important for policy makers to ensure that whether the environment is a common-pool or common-sink resources, they are not over-exploited but has to be guided very diligently to avert the problems of the tragedy of the commons

There are various reasons why the environment should be regarded as policy problems and I will enumerate and elaborate on a few in this paragraph. Environmental problems are transboundary in nature. As I have stated earlier, problems such as climate change, ozone depletion etc is not limited to a particular location but affects each and every individual living on the earth. This therefore calls on collective effort in combating these menaces and not just leaving it to be the problem of a particular state only. Many environmental problems are also very complex and full of uncertainty. The consequences of most environmental problems are not fully known. A clear example is the case of genetically modified (GM) foods. The effects of most of the chemicals on the health of humans are not fully known and this is one of the reasons GM foods are not encouraged. One other major concern in environmental management is the consequences from actions or inactions of policy makers and this can be a major political obstacle to environmental governance. It is a fact that, most environmental policies are made by government agencies and almost all governments are short sighted in the sense that all they care about is the retention of political power in the short term. This short sightedness is a major hindrance to environmental governance. An important political hindrance is explained by the 'pluralist model'. This model regards environmental policy as a kind of competition between various groups, and each group tend to use the 
resources at their disposal to influence environmental policy. This theory in fact makes environmental policy formulation very difficult, it is an indisputable fact that most government especially in liberal states will take account the objectives of producer groups because whatever decision it takes will go a long way to influence the economy and it can affect its popularity among the general populace.

It is very important to achieve policy change and there are various situations or scenarios when policy changes are most likely to happen. According to Down (1972), in every policy formulation, there is a stage he termed 'Issue Attention Cycle'. This is a stage in the formulation process where the public and the media's attention is drawn to the policy and it is at this stage that environmental policy makers are expected to enforce major structural changes that will permanently bring about the acceptance of their policies by all. The second situation where environmental policy can be enforced is the effect of exogenous changes (Smith, 1993: 93-7). Major exogenous change can be the emergence of a sudden crisis. For instance the 1979 nuclear reactor meltdown of the Three Mile Island plant and the further 1986 accident at Chernobyl prompted a major debate in the nuclear energy field and this led to a major policy on the use of nuclear power to generate energy. Other exogenous factor is the emergence of new environmental social movements or pressure groups. The activities of this pressure group are so extensive and important in environmental policy formulation that government and global policy makers have no option than to consult them when formulating policies. This has been a major victory in the area of environmental policy formulation. There are various pressure groups in the world such as Green Peace, Working for Water etc.

Environmental governance as a system of government is deeply embedded in stakeholder consultation with various groups and agencies. Governance as a word is deeply rooted in consultation because environmental problems do affect almost everyone. Environmental governance is therefore evolving from governing by hierarchy where governments follow the traditional bureaucratic process of service delivery to the general public to governing by network where government's process is no longer the direct delivering of public services but rather having to consult various external stakeholders and partners and allow them to take active part in the delivering of the particular public good. Dealing with stakeholders however needs to be done with caution as many NGO's and other non-state agencies most of the times may have their own selfish agenda. It is therefore important for partnership to be evaluated in order to avoid bad deeds and to allow transparency, accountability and growth or development.

Environmental governance is classified into global level governance, national level governance, regional level governance and local level governance. Global level governance is transnational in nature and it is perhaps one of the levels of environmental governance where stakeholder consultation has received the highest support. A clear example of stakeholder consultation at the global level was the development of the WEHAB Initiative. WEHAB means water, energy, health, agriculture, and biodiversity initiative. This initiative organized by the United Nations brought about major state and non-state stakeholders to work towards a common goal. Regional level governance basically deals with supporting various countries to help implement policies that will achieve sustainable development in the long term. National level governance is essential in that it aims at fostering sub-national governmental policy to align to Regional and Global policy of sustainable development. For instance Agenda 21 required all governments to establish a National Strategy for Sustainable Development (NSSD). NSSD was the platform that aims at integrating various sectors and ensure there is an effective stakeholder consultation and participation within various national governments. Finally, local level government deals with empowering the local community through education and this was successfully implemented by the World Bank through an initiative known as Direct Community Support approach. This approach reaches out to local communities through an already established social system in the local community.

The involvement of various stakeholders in environmental governance decision making finally introduces an important concept know as co-management. There are various definitions of co-management but for the sake of this journal I will use the concept as adopted by the World Conservation Congress. They define co-management as "a partnership in which government agencies, local communities and resource uses, nongovernmental organizations and other stakeholders share, as appropriate to each context, the authority and responsibility for the management of a specific territory or a set of resources" (quoted in Berkes 1997: 5). Comanagement therefore is seen in two ways, firstly, as a way of empowering local communities to have a say in the management of resources and secondly as an essential partnership between government agencies and resource users. Co-management is thereby seen as a compromise between the concern of governments for effective resource utilization and protection and the concern for the provision of equal opportunities and self control for resources uses

Co-management principles go beyond mere decentralization to the delegation of authority to resources users. According to Hersoung and Ranes (1997), co-management is more than consultation but that the resource users or the delegated institution does not only have direct role in joint decision making but they also have the equal opportunity to promulgate and implement regulatory decisions at their areas of jurisdiction. The only way of making people responsible is by making them feel responsible for their actions and inactions, and this can be 
achieve by making them a part of the decision making process and this is exactly what co-management seeks to achieve.

I will end this section by saying that, co-management as a management tool can only be effective when both parties involve have mutual respect and trust for each other. Symes (1997) recognized these truth and said co-management should be seen as an equal partnership where each party has equal right and responsibility. He therefore postulated that autonomy of state institutions and the other stakeholders in their areas of responsibility is fully respected by all.

\section{Study Context And Methodology}

The methodology employed for this research is the case study approach and the analysis of secondary data as well as face to face interview.

The mining industry in Ghana accounts for 5\% of the country's GDP and among this, gold mining accounts for $37 \%$ of the total minerals. Africa has a long history of Gold mining since pre-colonial era (Junner, 1935). According to Agbensinyale (2003), Africa is the largest producer of gold in the world, and also the continent holds $37 \%$ of the world's reserve base of Gold (Akabzaa et al., 2007). Ghana was known as the Gold Coast under British Colony before 1957. This attracted European interest in the country and this led to the eventual colonisation of the country by the British. Currently, Ghana is the second largest producer of gold in Africa (Kesse, 1980; Agbesinyale, 2003).

Obuasi is a town synonymous to gold mining in Ghana. The mention of Obuasi is like saying gold mining. The Obuasi mine was formally called Ashanti Goldfields, currently it is known as AngloGold- Ashanti Mine. Obuasi is located in the Ashanti Region of Ghana. It is the second largest city after Kumasi. Kumasi is the capital city of the Ashanti Region of Ghana. Towns surrounding Obuasi are predominant by agricultural activities. Due to the mining activities in the town, the town is a heterogeneous community with inhabitants coming from various part of Ghana and its neighbouring countries as well as foreign countries (Konings, 1980).

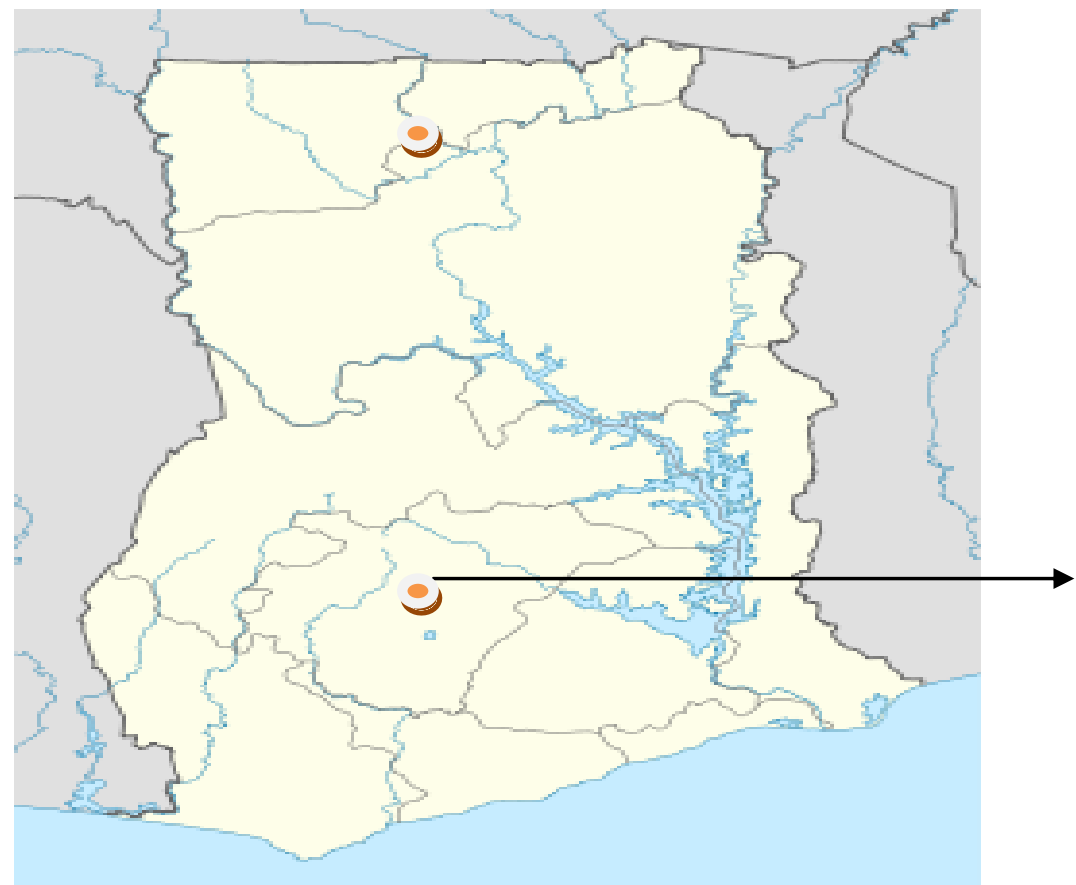

Obuasi Community

Fig 1(above): A map layout of the location of Obuasi Gold Mine on map of Ghana.

Before the colonization of Ghana by the British, the local communities in and around Obuasi were actively engaged in mining of reefs and panning gold from streams. The first concession of gold mining to be awarded was on $4^{\text {th }}$ June, 1875 by Monsieur Marie Joseph Bonnat, a French national (Junner, 1935; Quashie et. al, 1981; Ayensu, 1998). This therefore shows how the local residence were actively making a living from the area before colonization and the eventual takeover of the gold in the ground after colonization by the government

Small scale mining activities has been ongoing for a long time in the Obuasi community, however in 1989, the Provisional National Defense Council (PNDC) legalized the activities of these small scale miners by the enactment of the PNDC Law 218 of 1989. This legislation recognized the activities of small scale miners. However, there has been various instances in Ghana were most of these small scale miners do not register their 
companies because of various reasons such as difficulty in acquiring the necessary documents and the long bureaucratic process they have to go through before they are recognized. Most of the youth in Obuasi are engaged in illegal mining (galamsey) activities so as to raise money for themselves and their family.
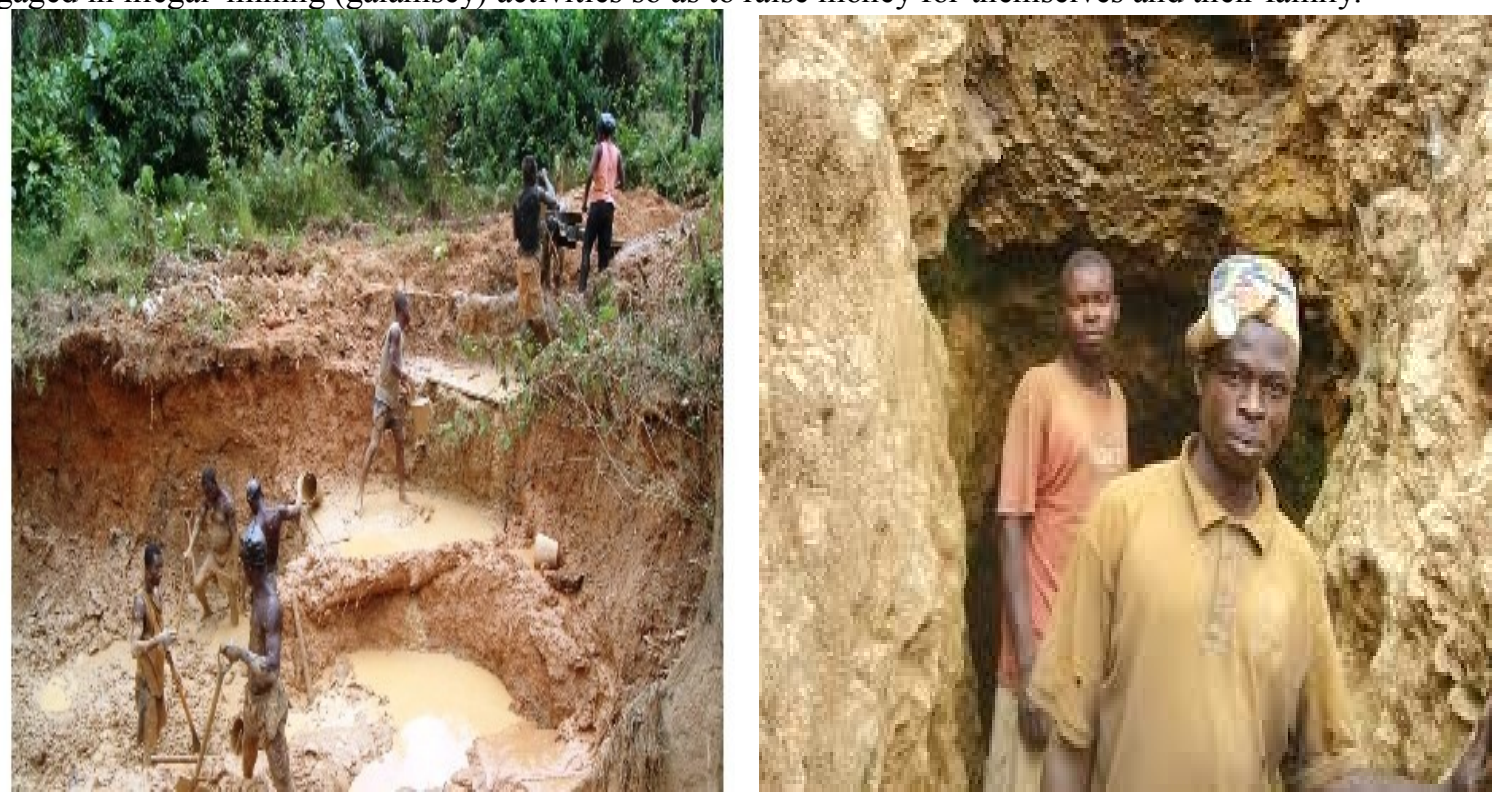

Fig 4 (above): Pictures of galamsey operators (adopted from myjoyonline.com)

The activities of these small scales miners are very detrimental to the environment because they use various dangerous chemicals such as mercury in their operation without any regards to the protection of the environment. Most of these miners put their lives at risk and most die on sites. They are however not bothered about their lives so much because of the financial gains from their activities. An account from one of the illegal miners shows how dangerous their activities are. He narrated that they have to dig a long hole into the earth until they get to a layer of rock known as the cross layer, and that it is after the cross layer that they are likely to get gold ores. On $18^{\text {th }}$ August 2012, Modernghana.com reported that in 2011 alone, about 300 people died of galamsey activities in Ghana. The activities of these illegal mining is very disturbing as they are gradually invading the concessions of most of the mining companies and some of the illegal miners have resorted to the use of sophisticated weapons such as cutlass, guns and clubs to protect themselves against intruders.

The activities of the illegal miners has a deep social and economic factors which has to be addressed thoroughly by the government and other non-state agencies else the country risk losing investors in the mining industry. Not only that, the local communities and in fact the entire country risk facing the consequences of these illegal activities as these miners are constantly polluting the environment with their crude and dangerous chemicals. The onus now lies on the state to find a holistic solution to this canker.

\section{Secondary Data Analysis}

This research came up with interesting findings. First of all, that there is a wide spread of inequality in the distribution of mineral wealth especially in Ghana Secondly that, Ghana receives disproportionally low revenue from mining companies as compared to foreign mining companies. The table below shows the ground rent payable by various mining companies in Ghana from 2004 to 2008

\begin{tabular}{|l|l|l|l|l|l|l|l|}
\hline Mine/Company & Concession & \multicolumn{5}{|c|}{ Amount in Ghana Cedis (1GHC $=\$ 1.5)$} \\
\cline { 3 - 7 } & Size $\left(\mathrm{km}^{2}\right)$ & 2004 & 2005 & 2006 & 2007 & 2008 \\
\hline AngloGold Ashanti (Obuasi & 334.27 & 167.54 & 167.14 & 167.14 & 167.14 & 167.14 \\
\hline AngloGold Ashanti (Bibiani) & 49.86 & 24.91 & 24.91 & 24.91 & 24.91 & 24.91 \\
\hline Anglogold Ashanti (Iduaprim) & 31.00 & 15.50 & 15.50 & 15.50 & 15.50 & 15.50 \\
\hline Golden Star Resources (Prestia/Bogoso) & 224.05 & 112.03 & 112.03 & 112.03 & 112.03 & 112.03 \\
\hline Goldfields Ghana Limited (Tarkwa) & 204.22 & 102.11 & 102.11 & 102.11 & 102.11 & 102.11 \\
\hline Abosso Goldfields Limited & 49.00 & 24.50 & 24.50 & 24.50 & 24.50 & 24.50 \\
\hline Ghana Manganese Limited & 175.93 & 87.97 & 87.97 & 87.97 & 87.97 & 87.97 \\
\hline Ghana Bauxite Co. Ltd & 29.39 & 14.70 & 14.70 & 14.70 & 14.70 & 14.70 \\
\hline Chirano Gold Mines Limited & 36.00 & & & & 18.00 & 18.00 \\
\hline
\end{tabular}

Fig 2: Ground rent payable by mining companies from 2004-2008 (Abdullai Darimani, 2011: 16) 
The Challenges of Environmental Governance: The Case of Mining Activities in Ghana ....

The next table shows the distribution of royalty payments among various actors

\begin{tabular}{|c|c|c|c|}
\hline \multicolumn{4}{|c|}{ ROYALTY PAYMENT/DISTRIBUTION } \\
\hline Beneficiary & \multicolumn{3}{|c|}{ Percentage share of total royalty collected per period } \\
\hline Mineral Dev fund & \multicolumn{3}{|l|}{10} \\
\hline \multirow[t]{3}{*}{ Total } & \multicolumn{3}{|c|}{100} \\
\hline & \multicolumn{3}{|c|}{ Distribution of the $10 \%$ at the level of local government and communities } \\
\hline & Share of the $10 \%$ & $\begin{array}{l}\text { Share of the } 10 \% \text { converted to } \\
100 \%\end{array}$ & Remarks \\
\hline $\begin{array}{l}\text { Office of the administrator of Stool } \\
\text { Land }\end{array}$ & 1 & 10 & For administrative cost \\
\hline District Assembly & 4.95 & 49.5 & Mine must be in district \\
\hline Stool & 2.25 & 22.5 & \multirow{2}{*}{$\begin{array}{l}\text { Mine is in traditional } \\
\text { stool/council area }\end{array}$} \\
\hline Traditional Council & 1.80 & 18.0 & \\
\hline Total & 10 & 100 & \\
\hline
\end{tabular}

Fig 3: Royalty Payment and Distribution. Adopted from (Abdullai Darimani, 2011: 16)

Finally, According to Darimani (2011: 17), total dividends payment to the government of Ghana for its automatic equity participation has been insufficient and unfortunately, these dividends have been fading. For instance:

- Dividend of $17 \%$ of total mining receipts was paid in 2005

- In 2006, this payment reduced to $12 \%$

- This further reduced to $6 \%$ in 2007

- $\quad$ Finally, in 2008 , it dwindled to a mere $1 \%$

It is very clear from the above results analysis that the level of royalties, ground price and dividends paid to the government of Ghana and the local communities by these mining companies is appalling and highly insignificant. This inadequacies has created numerous problems in most mining communities in and around the Obuasi area

\section{Discussion And Evaluation}

The issue of mining has received global concern and has been discussed on various global platforms. The above case study however shows a country struggling to manage the mining industry. The various mining companies pay less in terms of royalties and other dividends. It shows a government seeking more foreign exchange to the detriment of its people. Principle 21 of the Stockholm Declaration describes nations as having "the sovereign right to exploit their own resources pursuant to their own environmental policies" (UNDP 1972; UNEP 1992). The problem with environmental governance is however not about its inability to manage its own mineral resources but about the lack of institutional capabilities which is unable to give effect to its policies and its stated environmental goals.

The environment and mineral resources are public goods in that, whatever pollution may come out from a particular mining site does affect the global environment. It is true that public investment in mineral resources bring many state and non-state actors together. Most of these organs and agencies have their own interest: First of all, private company comes in to make profit from the minerals they mine. Secondly, the state comes in to make revenue and also to protect the interest of the public. Thirdly communities are also involved with the aim of improving their livelihood and social interest. The multiple and public nature of mining or mineral resources raises huge contestation that needs global audience. These multiple nature brings in mind the idea of collaborative governance. Collaborative governance is important in mineral resources because it will help address holistically the issue of the minerals sustainable extraction, utilization and equitable distribution. Agencies involve in cooperative mineral resource management basically come together to protect their interest and that of the environment and the general population through redistribution power, benefits and burdens of mining as well as knowledge and skills.

From the above paragraph, it is very obvious that collaborative environmental governance has emerged as a kind of paradigm shifts that will help in addressing inequalities in the mining industry. It is a common practice in most international mining industry that Environmental Impact Analysis (EIA) becomes an integral procedure of their activities. EIA is meant to provide sound environmental and sustainable development by incorporating into development project environmental issues (Hunter et al. 1998; Jain et al. 1993). Incorporated into EIA is Social Impact Assessment (SEA). SEA is defined by Vanclay and Burge (1996) as "the process of assessing or estimating, in advance, the social consequences that are likely to follow from specific policy actions or project development' SEA is meant to take into considerations all social and culture consequences into any 
project that affects a population in one way or the other. SEA and EIA are therefore important tools that can help regulate mining activities and also make sure mining activities adhere to the culture and norms of a particular jurisdiction they are operating. It will also come up with negative consequences of a particular mining activity and solution as to how to solve such negative consequence. A closer look at Ghana's' environmental policy is surprisingly very silent on EIA and SEA analysis in the mining industry and this is very worrying and obviously it is one of the reason why illegal mining activities are so prominent in mining communities. This is because most of the mining companies does not take into consideration the needs of the local community they are operating in.

There will be the need for the government to come up with practical policies that will address practical problems in the Ghanaian mining industry to make sure the royalties and other dividends paid by the mining companies are significant as compare to the level of mineral resources they mine. Government has to be seen as leading the way for other NGO and non-state agencies to follow or adhere to.

In terms of collaborative governance, there is the need for local communities in and around mining communities as in our case study above, the Obuasi community to be actively involved in the entire management process of the mining companies. The mining companies do not operate in a vacuum they are always located in a local community or municipality, and as soon as any mineral is located within their jurisdiction, obviously they (the local community) expect some kind of social and financial improvement in their lives and community. The financial capabilities of the mines may not be able to ensure the community's dreams and aspirations are met, but it will be practically impossible to explain this to the local folks. However when they are involved in the management activities, they will see how things are for themselves and they can better appreciate what is going on. There is therefore the need for the governments to educate the local mining community and make sure they have access to adequate information on the ground by involving them in the day to day running of the mining industry.

Another important factor is that, the mining companies must sign a memorandum of understanding that will bind them to the provision of social amenities and help to the community they are involved in. When this is then, the local community will have confidence in whatever is going on in their traditional land and they will better cooperate with the authorities.

A worrying concern is the issue of illegal mining activities in the Obuasi community and other mining areas in Ghana. It is an undisputable fact that Africa is plaque by poverty and so many people engage in so many illegal activities in other to make ends meet. This does not however allow individuals to put the law into their hands and do whatever they deem appropriate. In environmental governance perspective, there are various ways of solving these menaces. In the case of Ghana, there is already an enactment of a law prohibiting the activities of this galamsey operators, however, the various government departments such as the Ministry of Environment, Mineral Resources and the Mineral Commission are not well equipped to enforce these laws. There is therefore the need for these government agencies and department to be better equipped to enforce the laws and regulation banning the activities of these galamsey activities. There will also be the need for the establishment of a special task force that will be trained and deployed specifically to these mining communities to ensure no individual or group is engage in any kind of illegal mining activity. An important solution to halt these illegal activities is to ensure the mining companies give quota of employment opportunities to local mining communities, this will help reduce employment especially in these mining communities and this can stop the youth from engaging in illegal mining to make a living.

There will also be the need for a full scale EIA and SEA to be conducted to help solve environmental, culture and social issues that these mining companies may cause by their activities.

\section{Recommendation And Concusion}

Environmental governance has been one of the difficult fields because the environment can be regarded as a complex organism with complicated processes which has no simple solution. Various scholars give recognitions of the importance of fully understanding the many different kinds of environmental conflicts and solving them thoroughly. O'Leary et al (2004: 324) concluded that environmental governance and environmental conflict resolution interventions are "complex systems embedded in even larger complex systems" From the beginning of this journal through to the case study, it has becoming increasing clear that, that the solution to environmental governance in the mining industry in Ghana can be solved by a bottom-up management process. There is the need for an intense public participation in environmental governance in Ghana. There is the need to better educate the local mining communities; in this case, in and around the Obuasi community by making available relevant data and making them part of the mining management committee or any other relevant committee. This will empower the local community and give them a sense of belonging and that will make them more responsible. This will help curb the problems caused by the activities of the galamsey operators. 
Relevant non state institutions as well as NGOs have to be involved actively in the mining industry. These NGOs may have their own interest but they do serve as an important bridge between the government and the local mining communities as well as the management of the mining companies. From local participation to the inclusion of NGOs, the next thing is for government to come up with policies and regulations that will empower various stakeholders in the mining industry. The underlying solution here will be collaborative environmental governance; where various actors are involved in the mining industry for the good of the industry.

Ghana is an immerging oil production country and has also been involved in gold and other mineral mining for some time now. There is therefore the need to come up with fair and firm legislation that will ensure the country benefits from its natural resources. The inclusion of EIA and SEA will be very crucial to protect the environment and also to meet the needs of its population as well as the local community. It is only by doing this that the present generation will benefits from its natural resource without depleting it and making sure the future generation have their fair share of the available resources.

\section{Bibliography}

[1]. Agbesinyale PK (2003). Ghana's Gold Rush and Regional Development: The Case of Wassa West District. (SPRING Centre, University of Dortmund)

[2]. Akabzaa, T.M., Seyire, J.S. and Afriyie, K. (2007). The Glittering Façade: Effects of Mining Activities on Obuasi and Its Surrounding Communities, Accra: Third World Network-Africa. Ake, C. (1981). A Political Economy ofAfrica, Essex: Longman.

[3]. Ayensu ES (1998). Ashanti Gold: The African Legacy of the World's Most Precious Metal (London: Marshall Publishing Ltd)

[4]. Berkes, F. (1997: 5). New and not-so-new directions in the use of the commons: co-management. The common property resource digest (no. 42). International Association for the study of Common Property, Indiana, USA

[5]. Burdge, R.J. and Vanclay, F., (1996). 'Social impact assessment: a contribution to the state of the art series', Impact Assessment, 14(1):59-86.

[6]. Daramani A. (2011: 16) University of Ghana Business School. PhD Research Thesis: Enhancing Collaborative Governance and Management of Extractive Industries for Equitable Wealth Distribution through sound Environmental Management in Africa. Accra Ghana

[7]. Hardgin, G. (1968). The tragedy of the commons. Science, New Series, Vol. 162, No. 3859 (Dec. 13, 1968), pp. 1243-1248

[8]. Hersoung, B. and S.A. Ranes (1997: 157-172). What is good for the fisherman is good for the nation: co-management in the Norwegian fishing industry in the 1990s. Ocean and Coastal Managment 32(2-3)

[9]. Hunter, D., Salzman, J. and Zaelke, D., 1998. International Environmental Law and Policy, Foundation Press, New York.

[10]. Jain, R.K., Urban, L.V., Stacey, G.S. and Balbach, H.E., (1993).Environmental Assessment, McGraw Hill, Austin.

[11]. Junner, NR (1935). "Gold in the Gold Coast" Ghana Geological Survey, Memoir, 4(5): 20

[12]. Konings, P (1980). "The Political Potential of Ghanaian Miners: A Case Study of the AGC Workers at Obuasi" Research Reports No. 9. File No.: Dp/HD8039.M73G5K83, Africana Section, the Balme Library, University of Ghana-Legon.

[13]. M Brandes and David B Brooks $(2005: 8)$ The Soft Path in a Nutshell. Oliver. University of Victoria, Victoria, BC

[14]. Nations Conference on the Human Environment (1972), (referred to as 'The Stockholm Declaration'), United Nations Development Programme, Stockholm. Available from http://www.unep.org._—_, 1999. Artisanal Mining for Sustainable Livelihoods, United Nations Development Programme, New York. Available from http://www.undp.org.

[15]. O’Leary, R., Nabatchi, T. and Bingham, L.B., 2004. 'Environmental conflict resolution', in R. Durant, D.J. Fiorino and R. O’Leary (eds), Environmental Governance Reconsidered: challenges, choices, and opportunities, MIT Press, Cambridge, Mass.:323-54.

[16]. Ojeda, L (2005); Gobernabilidad en la Conservación de los Recursos Naturales (Governance of Natural Resources Conservation); Red ECOUF; Universidad de La Florida

[17]. Quarshie, LAK, Pentsil, BK, Kesse, GO and Thompson, PTA (1981) Report of the Committee for Increased Gold Output in Ghana. Revised Edition. New York. DP/UN/GH-78-003/3

[18]. Symes, D. (1997). Co-management in marine and coastal fisheries. Paper presented at the Conference on Co-management: cooperation in management of the North Sea and Wadden Sea fisheries, Groningen, The Netherlands, 9-10 January 1997.

[19]. United Nations Development Programme, 1972. Declaration of the United

[20]. United Nations Environment Program, 1992. Rio Declaration on Environment and Development (1992), United Nations Environment Program, Rio de Janeiro. Available from http://www.unep.org.

[21]. United Nations General Assembly (March 20, 1987). "Report of the World Commission on Environment and Development: Our Common Future; Transmitted to the General Assembly as an Annex to document A/42/427 - Development and International Cooperation: Environment; Our Common Future, Chapter 2: Towards Sustainable Development; Paragraph 1". United Nations General Assembly. http://www.un-documents.net/ocf-02.htm. Retrieved 1 March 2010. 